\title{
Alih Kode Guru dalam Pembelajaran Bahasa Indonesia Kelas VIII A SMP Negeri I Remboken
}

\author{
Yossy Jonathan Mamahit, Wimsje Revlin Palar, Oldie Stevie Meruntu
}

Jurusan Pendidikan Bahasa dan Sastra Indonesia, Fakultas Bahasa dan Seni, Universitas Negeri Manado

yossymamahit07@gmail.com,wimsjepalar@unima.ac.id,oldiemeruntu@unima.ac.id

\begin{abstract}
Abstrak. Bahasa Indonesia merupakan bahasa pengantar di dalam kegiatan belajar-mengajar di kelas. Namun, dalam penggunaannya di kelas, guru masih saja beralih kode. Tujuan penelitian ini ialah untuk mendeskripsikan alih kode yang terjadi dalam penggunaan bahasa Indonesia guru dalam interaksi belajar mengajar serta untuk mengejar faktor penyebab terjadinya alih kode. Metode yang digunakan dalam penelitian ini ialah metode kualitatif. Untuk megumpulkan data, teknik yang digunakan ialah observasi dan rekam. Untuk menganalisis data, teknik yang digunakan ialah transkrip data rekaman reduksi data. Sumber data penelitian ialah guru bidang studi bahasa Indonesia. Hasil penelitian menunjukan bahwa bentuk-bentuk alih kode yakni alih kode bentuk kalimat, alih kode antar kalimat dan alih kode intra kalimat muncul dalam pembelajaran dalam kelas oleh guru. (1) Alih Kode yang terjadi dalam penggunaan bahasa Indonesia oleh guru di kelas adalah alih kode bahasa melayu Manado (BMM); (2) Bahasa Indonesia yang digunakan adalah Bahasa Indonesia Baku (BIB) yang bercampur kode dengan BMM bahkan campur kode antara BIB, BII, dan BMM; (3) Alih kode terjadi pada konteks yang berkaitan dengan kehidupan siswa. Selain itu, faktor penyebab alih kode juga terbukti mempengaruhi guru sehingga muncullah alih kode dalam kegiatan belajar mengajar dalam kelas.
\end{abstract}

Kata Kunci: : Alih Kode, Pembelajaran, Bahasa Indonesia

\section{PENDAHULUAN}

Bahasa sangat penting dalam kehidupan manusia karena dengan bahasa seseorang dapat menyampaikan suatu maksud atau tujuan kepada orang lain. Bahasa yang digunakan itu memiliki sistem bunyi dan makna. Kridalaksana (1985:12) mengemukakan setiap orang menggunakan bahasa, karena bahasa adalah sistem bunyi yang memiliki makna serta digunakan dalam berkomunikasi antar sesama umat manusia. Jelaslah sistem bunyi yang bermakna merupakan persyaratan dalam berkomunikasi untuk menyampaikan pesan, perasaan, maksud, ide, dan pendapat untuk orang lain

Di Indonesia, bahasa dapat dikelompokkan atas bahasa Indonesia, bahasa Daerah, dan bahasa Asing. Di dalam kedudukannya sebagai bahasa Negara karena bahasa Indonesia telah dicantumkan di dalam UUD 1945. Berdasarkan UUD 1945 Bab XV pasal 36 Fungsi bahasa Indonesia salah satunya adalah Bahasa pengantar resmi di lembaga-lembaga pendidikan, dalam dunia pendidikan bangsa Indonesia harus menggunakan bahasa Indonesia agar generasi selanjutnya dapat menggunakan bahasa Indonesia dengan baik dan benar dalam kehidupannya.

Selain itu, bahasa Indonesia merupakan salah satu mata pelajaran pokok di sekolah. Mata pelajaran Bahasa Indonesia berdasarkan Kurikulum 20013 adalah program untuk mengembangkan pengetahuan, keterampil berbahasa dan sikap positif terhadap bahasa Indonesia dengan tujuan untuk membimbing siswa supaya mampu menggunakan bahasa Indonesia dengan baik dan benar dalam berkomunikasi baik secara langsung maupun tidak langsung. Bahasa yang baik adalah bahasa yang sesuai dengan situasi dan kondisi. Sebagai alat komunikasi, bahasa harus dapat efektif menyampaikan maksud kepada lawan bicara. Bahasa yang benar adalah penggunaan bahasa yang sesuai dengan kaidah bahasa.

Dalam pembelajaran sering kali guru atau tenaga pengajar belum menggunakan bahasa Indonesia sebagaimana fungsi bahasa yang diatur dalam UUD 1945 Bab XV pasal 36. Begitu pula guru yang 
mengajar mata pelajaran Bahasa Indonesia di sekolah. Semestinya guru harus menggunakan bahasa Indonesia. Tetapi masih sering ditemukannya penggunaan bahasa melayu manado dalam pembelajaran. Misalnya, dalam mengajarkan materi Dongeng, guru menggunakan bahasa Indonesia sebagai penjelasan pembuka dalam pembawaan materi. Tetapi ketika menjelaskan lebih dalam tentang Materi pembelajaran , guru menggunakan bahasa Melayu Manado. seperti dalam tuturan berikut

1..Nah tu tadi cerpen pe pengertian. Skarang ngoni so tau apa itu dongeng?

"Nah itu tadi adalah pengertian dongeng. sekarang kalian sudah paham apa itu dongeng ?"

Kalimat ini muncul setelah guru menjelaskan menggunakan bahasa Indonesia tetapi beralih kode dalam bahasa Melayu Manado, untuk menanyakan apakah siswa paham dengan materi yang dibawakan guru.

2. Dongeng apa yang ngoni tau?

" dongeng apa yang kalian tahu?

Guru bertanya menggunakan bahasa Melayu Manado tentang jenis dongeng apa yang diketahui siswanya.

3. Aduh, Nintau kang?

"Aduh ,Tidak tahu ya?"

Ketika guru menjelaskan dan siswa hanya diam kalimat di atas biasanya sering terucapkan oleh guru.

4. so mangarti Ngoni seтиа?

"Sudah mengerti kalian semua "

Guru bertanya apakah siswa-siswanya sudah paham dengan penjelasan yang diajarkan guru.

Dari contoh-contoh yang tersaji di atas, Alih kode adalah hal yang lazim digunakan guru bahasa Indonesia di SMP Negeri 1 Remboken saat menjelaskan Materi pembelajaraan. Menurut Allan Bell (dalam Coupland dan Adam, 1997:240) variasi bahasa adalah salah satu aspek yang paling menarik dalam sosiolinguistik. Prinsip dasar dari bahasa variasi bahasa ini adalah penutur tidak selalu berbicara dalam cara yang sama untuk semua peristiwa atau kejadian. Interferensi , intergrasi alih kode dan campur kode ,dan bahasa gaul menyebabkan terjadinya variasi bahasa. Variasi bahasa yang sering muncul dalam proses belajar mengajar biasanya adalah alih kode.

Alih kode sengaja dilakukan guru untuk memudahkan siswa memahami materi yang disajikan berkaitan dengan Dongeng. Oleh karena itu, peristiwa alih kode yang dilakukan guru bahasa Indonesia menarik untuk diteliti sebagai fenomena berbahasa yang unik.

Berdasarkan contoh di atas, pemakaian bahasa Indonesia dapat beralih ke bahasa melayu manado atau ragam lainnya. Peralihan bahasa yang digunakan ke bahasa yang lain tersebut adalah alih kode (Ohoiwutun 2007:71) mengatakan alih kode, yakni peralihan pemakaian dari suatu bahasa atau dialek ke bahasa atau dialek lainnya.

Bertolak dari latar belakang masalah diatas, peneliti ingin menggali lebih dalam tentang wujud alih kode yang terjadi dalam pembelajaran bahasa Indonesia di kelas VIII A SMP Negeri I Remboken.

\section{METODE}

Dalam penelitian deskriptif kualitatif mengacu pada suatu maksud atau arti, konsep-konsep, defenisi, karakteristik, simbol-simbol, dan deskripsi dari berbagai hal. Boglan dan Taylor (dalam Moleong, 2010: 4), menjelaskan metode kualitatif merupakan sebuah prosedur penelitian yang menghasilkan data deskritif berupa kata-kata tertulis maupun lisan dari orang-orang maupun prilaku yang dapat diamati. Pengamatan tersebut berhubungan dengan orang-orang tersebut dalam bahasanya dan peristilahannya.

Dengan demikian metode ini sesuai digunakan untuk meneliti alih kode guru dalam pembelajaran bahasa Indonesia di SMP Negeri 1 Remboken.

Subjek penelitian sebagai orang yang diamati sebagai sasaran penelitian (Moeliono, 1993: 862). Berdasarkan pengertian tersebut peneliti mendeskripsikan subjek peneilitian bahasa sebagai pelaku bahasa yang merupakan sasaran pengamatan atau informan pada suatu penelitian yang diadakan oleh 
peneliti. Subjek pada penelitian ini adalah Guru Bahasa Indonesia Kelas VIII A SMP Negeri 1 Remboken.

Objek penelitian merupakan hal yang menjadi titik perhatian dari suatu peneltian. Titik penelitian tersebut berupa subtansi atau materi yang diteliti atau dipecahkan permasalahannya menggunakan teoriteori yang bersangkutan (teori morfologi dan sematik. Menurut Chaer (2007: 17), objek kajian linguistik dibagi menjadi tiga yaitu kajian struktur internal bahasa, kajian terhadap pemakaian bahasa, serta kajian pengajaran bahasa. Berdasarkan penjelasan di atas, penelitian ini adalah Alih kode dalam pengajaran Guru Bahasa Indonesia di Kelas VIII A SMP Negeri 1 Remboken.

Pada penelitian kualitatif, peneliti memiliki kedudukan khusus, yaitu sebagai perencana, pelaksana pengumpulan data, analisis, penafsiran data, serta pelapor hasil penelitiannya (Moleong, 2010 :168). Kedudukan penelitian menjadi instrument kunci yang mengumpulkan data berdasarkan kriteriakriteria yang dipahami. Kriteria tersebut berdasarkan aspek Alih kode dalam pengajaran Guru Bahasa Indonesia di Kelas VIII A SMP Negeri 1 Remboken. Oleh karena itu peneliti secara langsung berperan aktif dalam proses penelitian. Hal itu dilakukan guna mendapatkan data-data yang sesuai dengan tujuan penelitian.

Sugiyono (2010:63) menyatakan pada penelitian kualitatif, pengumpulan data dilakukan pada natural setting dan teknik pengumpulan data lebih banyak pada observasi berperan serta, wawancara mendalam, dan dokumentasi. Mengacu pada pengertian tersebut, peneliti mengartikan teknik pengumpulan data sebagai suatu cara untuk memperoleh data melalui beberapa langkah, yaitu: observasi, wawancara dan dokumentasi.

1) Observasi merupakan kegiatan pengamatan yang dilakukan oleh peneliti selama penelitian berlangsung.

2) Wawancara dilakukan pada Guru Bahasa Indonesia Kelas VIII A SMP Negeri 1 Remboken untuk mengetahui faktor penyebab terjadinya alih kode dalam pengajaran. Wawancara dilakukan setelah melakukan observasi pada penelitian.

3) Dokumentasi merupakan cara dilakukan untuk menyediakan data-data dengan bukti yang akurat dari pencatatan sumber informasi khusus.

Langkah-langkah tersebut berfungsi untuk mempermudah peneliti dalam proses pemerolehan data. Analisis data merupakan proses mencari dan menyusun secara sistematis data yang diperoleh dari hasil wawancara, catatan lapangan, dan dokumentasi (Sugiyono,2010:89). Analisa data penelitian ini memiliki dua tujuan. Tujuan yang pertama adalah untuk mengidentifikasi faktor apa saja yang mempengaruhi terjadinya alih kode dalam pengajaran Guru Bahasa Indonesia di Kelas VIII A SMP Negeri 1 Remboken dan tujuan yang kedua adalah untuk mendeskripsikan bagaimana pengaruh alih kode dalam pengajaran Guru Bahasa Indonesia di Kelas VIII A SMP Negeri 1 Remboken.

Data yang diperoleh kemudian dituangkan dalam bentuk tulisan dan analisis dengan cara-cara sebagai berikut :

1) Reduksi Data, data yang diperoleh dalam lapangan di rangkum dan difokuskan pada hal yang penting kemudian disusun kembali secara sistematis sehingga lebih mudah dikendalikan. Dengan cara, memilih dan memisahkan data yang masiih bersifat umum, sehingga diperoleh data yang nanti akan digunakan.

2) Penyajian Data, data yang sudah dipilih kemudian disusun secara lengkap dan di sajikan dalam bentuk data mentah. Hal ini perlu dikuasai oleh peneliti.

3) Verifikasi , semua data yang ada di verifikasi atau ditinjau kembali apakah benar-benar sudah sesuai ataukah perlu menambahkan data baru atau tidak.

4) Kesimpulan, ketika data sudah diolah dengan ketiga hal diatas maka kesimpulan diperlukan untuk mendapatkan hasil yang tepat dan akurat.

\section{HASIL DAN PEMBAHASAN}

Bentuk-bentuk alih kode guru dalam proses belajar mengajar di deskripsikan sebagai berikut :

\section{Alih kode bentuk kalimat}

+ Dongeng adalah ... 
$-\quad$ aduh nin tau kang?
aduh tidak tahukah ?'

Guru bertanya apakah siswa tahu tentang materi yang sementara dipelajari. Tetapi ternyata siswa tidak tahu apa pengertian dongeng. Karena, siswa hanya diam ketika ditanya.

+ Yang kalian tau setan - setan

- ngoni tau Cuma kancil

'kalian ketahui hanya kancil'

Guru memberikan pernyataan kepada siswa yang tidak tahu bahwa mitos itu termasuk dalam dongeng. Karena, anak-anak hanya tahu Kancil yang adalah cerita fabel.

+ Ada anak - anak yang suka setan - setan ?

- ada anak ba uni setan - setan, horor - horor

' Ada anak menonton setan - setan, horor - horor

Guru memberikan penjelasan kepada siswa yang ternyata tahu cerita horor atau mite tetapi, tidak tahu jikalau itu salah satu jenis dongeng.

+ Banyak malin kundang ?

- mangaku jo malin kundang

'mengaku saja malin kundang'

Guru mencoba menggali kepribadian siswa apakah ada yang mirip seperti tokoh Malin Kundang yang durhaka terhadap orang tuanya.

+ mengapa dia dikatakan durhaka?

- kiapa dang dia anak durhaka?

' mengapakah dia anak durhaka? durhaka.

Guru kembali menjelaskan kemudian diikuti pertanyaan kenapa si Malin Kundang dikatakan anak

+ jelas anak - anak?

- ada yang mo ba tanya

'adakah yang akan bertanya'

Setelah menjelaskan materi pembelajaran guru bertanya kepada siswa jika ada yang ingin bertanya.

\pm Lalu abis latar apa? Amanat

- dengar bae - bae

'dengarkan baik - baik'

Sebelum menjelaskan guru bertanya kepada siswa dan menyuruh mereka untuk menyimak dengan baik.

\section{Alih kode antar kalimat}

\pm setiap orang mempunyai karakter beda-beda

- ada pamarah, ada pambae, ada koncudu

' ada pemarah, ada baik, ada pelit'.

Guru menerangkan bahwa setiap orang itu berbeda-beda, tidak semuanya sama.

- itu dia pe tema, tema baca dulu baru dapa tau

'itu adalah tema. Tema dibaca dahulu kemudian dapat diketahui'.

Guru menjelaskan tentang tema, disuruhnya dibaca terlebih dahulu agar siswa dapat memahami apa itu tema.

- ih... ba uni sandiri ley, kalo ba uni banyak - banyak

' ih menonton sendiri saja, kalau menonton banyak orang' 
- kalo ba uni sandiri brenti ley, kita sandiri dang'

'Kalau menonton sendiri berhenti saja, saya sendiri kah'

Guru memancing pembicaraan dengan siswa terkait tayangan televisi tentang cerita menyeramkan. Serta, guru memberikan pernyataan-pernyataan bahwa ternyata siswa tidak berani menonton setan-setan sendiri.

+ ada berapa macam penokohan...

- ibu mo tanya banyak yang nin tau?

' ibu bertanya banyak yang tidak mengetahui'

Setelah guru menjelaskan macam penokohan ternyata banyak yang tidak tahu istilah-istilah bahkan arti dan jenis dari penokohan itu.

\section{Alih kode intra kalimat}

+ Rata - rata di sini malin kundang?

- angka tangan

' angkatlah tangan'

Guru bertanya apakah ada siswa yang tahu cerita Malin Kundang disuruhnya siswa merespon dengan mengangkat tangan.

+ jadi disini banyak anak - anak malin kundang

- anak nyanda balajar dirumah, yang Cuma minta - minta doi padia pe mama

' anak tidak belajar di rumah, hanya meminta - minta uang pada Ibunya!

- kong nyanda datang - datang di sekolah.

'kemudian, tidak mau masuk ke sekolah'

- ba cao

' melarikan diri dari sekolah'

Guru mengatakan kepada siswa jikalau karakter-karakter buruk itu diumpamakan seperti Malin Kundang. Yaitu sikap malas datang ke sekolah atau hanya bolos sekolah.

+ itu namanya malin kundang

- ada barapa orang di sini malin kundang?

'berapa orang di sini malin kundang?

Guru menanyakan lagi siapa siswa yang seperti Malin Kundang dengan sedikit sindiran.

- so keluar

'sudah keluar'

Guru mengatakan bahwa siswa yang mirip Malin Kundang adalah siswa yang responnya keluar dari kelas.

+ penokohan ada protagonis, tritagonis

- bae nyanda jaha nyanda

' baik tidak, jahat tidak'

Guru menjelaskan tentang penokahan dalam sebuah cerita. Setelah penokohan tritagonis, adalah tokoh yang dikatakan baik tidak, jahatpun tidak.

\pm Di Tv juga berani ba uni setan - setan.

'untuk menonton'

Guru bertanya kepada siswa apakah berani untuk menonton acara setan-setan.

\pm Siapa yang bilang tadi? Dia anak durhaka

Siapa yang katakan tadi ? Dia anak durhaka.

Guru mengatakan bahwa murid yang mengeluarkan kata-kata tidak baik merupakan anak durhaka. 


\section{Faktor-faktor penjelas}

Bertolak daari hasil analisis data di atas, alih kode yang terjadi pada penggunaan bahasa Indonesia guru di kelas dapat dijelaskan sebagai berikut :

a. Penggunaan bahasa Indonesia oleh guru di kelas tidak sepenuhnya menggunakan bahasa Indonesia baku (BIB). Guru masih saja bercampur dengan bahasa Indonesia ragam informal atau ragam percakapan (BII) sebelum guru beralih kode ke bahasa melayu Manado (BMM). Pada contoh (1) sebelum terjadi alih kode, guru masih menggunakan bahasa Indonesia baku. Dongeng adalah ...., setelah itu guru beralih kode ke BMM aduh nin tau kang 'aduh tidak tahukah'. Pada contoh (2) sebelum terjadi alih kode, guru menggunakan BII seperti kata berupa yang seharusnya berapakah. Setelah itu, guru beralih kode ke BMM butul no ada empat 'betul sekali ada empat'. Pada contoh lainnya ragam BII seperti tau pada kalimat contoh fable yang ada di Tv yang kalian tau yang seharusnya ketahui. Setelah itu, guru analisis kode ke BMM ngoni tau Cuma kancil 'kalian ketahui hanya kancil'. Alih kode 'ada pamarah, ada pambae, ada koncudu terjadi setelah guru bercampur kode dengan BII setiap manusia punya karakter beda - beda. Kata BII punya seharusnya mempunyai dan beda - beda seharusnya berbeda - beda.

b. Penggunaan bahasa Indonesia, agar guru di kelas tidak sepenuhnya menggunakan bahasa BIB. Karena guru masih bercampur kode dengan BMM dan BII Sebelum beralih kode ke BMM. Pada contoh di atas, campur kode yang terjadi adalah ada anak - anak yang suka ba uni setan - setan. Kata ada ba uni 'menonton' dan BII ada yang seharusnya adalah dan suka yang seharusnya menyukai. Kemudian guru beralih kode ke BMM ih, ba uni sandiri ley, kalo ba uni banyak boleh jo' ih, menonton sendirian lagi. Kalau menonton banyak (orang) boleh saja'. Campur kode BMM seperti disini banyak malin kundang? Angka tangan. Kata BMM angka tangan yang seharusnya angkat tangan. Kemudian guru beralih kode ke BMM mangaku jo malin kundang 'mengaku saja malin kundang. Alih kode juga terjadi setelah campur kode BMM kiapa dank dia anak durhaka. Alih kode yang dimaksud adalah dimana di ape sombong 'kesombongannya dimana?'. Alih kode anak nyanda balajar di rumah Cuma minta - minta doi pa dia pe mama 'anak yang tidak belajar di rumah, hanya meminta - minta uang kepada ibunya. BMM masih mendominasi penggunaan bahasa guru di kelas ketika pembelajaran berlangsung baik yang berbentuk campur kode maupun alih kode.

Peran bahasa Indonesia sebagai Bahasa pengantar dalam pembelajaran di kelas patut di rumuskan kembali. Apakah yang dimaksud dengan bahasa Indonesia adalah bahasa Indonesia dengan ragamnya atau bahasa Indonesia baku. jadi yang dimaksud adalah menggunakan bahasa Indonesia dengan ragamnya. Misalnya ragam informal, hal ini dimaknai bahwa guru dapat menggunakan bahasa Indonesia tidak baku yang didirikan dan diluluhkannya awalan seperti coba yang seharusnya mencoba kecuali dalam bentuk pasif.

Campur kode BMM dalam penggunaan bahasa Indonesia adalah hal yang tidak mungkin dapat diterima karena hal ini dapat merusak peran bahasa Indonesia sebagau bahasa pengantar di dalam dunia pendidikan sesuai kedudukannya sebagai bahasa Negara. Kecuali jika kosa kata BMM dapat memberikan kontribusi pada pematerian bahasa Indonesia seperti halnya bahasa daerah lainnya. Apalagi menghadap masa kelokalan (otonomi daerah), bahasa daerah diharapkan dapat mendukung pengembangan bahasa dalam.

Alih kode yang telah digambarkan di atas, pada umumnya terjadi pada konteks jika guru membicarakan masalah yang berkaitan dengan kehidupan siswa atau guru itu sendiri. Pada masalah kehidupan pribadi siswa seperti ketidaktahuan siswa terhadap materi, seperi aduh nin tau, karakter siswa, seperti pamara, pambae, koncudu, hal - hal yang di minta untuk dilakukan siswa seperti angka tangan, kebiasaan anak seperti anak nyanda balajar, Cuma minta - minta doi, dan sebagainya.

\section{Faktor yang mempengaruhi beralih kode}

Ada beberapa faktor yang mempengaruhi sehingga terjadi alih kode seperti yang sudah dikemukakan sebelumnya pada bab dua. Dalam hal ini faktor-faktor tersebutpun nampak dilakukan oleh guru.

1. Pembicara atau penutur. Guru selaku penutur melakukan alih kode agar siswanya mudah memahami apa yang guru tersebut jelaskan. 
2. Pendengar atau lawan tutur. Siswa yang adalah lawan tutur memiliki pemahaman yang lebih rendah dibandingkan guru sehingga, mau tidak mau guru harus beralih kode.

3. Perubahan situasi dengan hadirnya orang ketiga. Guru mengubah situasi dari resmi menjadi tidak resmi seringkali terjadi ketika guru menerangkan materi dan salah satu siswa tiba-tiba menyela. Misalnnya : 'bu isin' lantas guru menjawab 'pigi jo'. Hal ini sangat sering terjadi.

4. Perubahan dari formal ke informal bahkan sebaliknya. Guru seringkali mengubah situasi seperti ini karena guru merasa penjelasan tentang materi yang dibawakannya lebih mudah dipahami oleh siswanya dalam situasi formal atau sebaliknya.

5. Perubahan topik pembicaraan. Ketika guru menanyakan atau memberi pernyataan tentang siswa secara pribadi otomatis guru beralih kode ke bahasa lain.

Dari hasil penelitian di atas dapat ditemukan bahwa terdapat alih kode yang dilakukan Guru bahas Indonesia kelas VIII A SMP Negeri 1 Remboken, ketika mengajar di dalam kelas. Hal ini bertujuan agar siswa lebih memahami tentang materi yang disampaikan oleh guru ketika mengajar di dalam kelas.

Alih kode merupakan suatu hal yang lazim terjadi bagi seseorang yang menguasai dua atau lebih bahasa. Alih kode seringkali muncul ketika penutur dan lawan tutur ada dalam situasi tertentu, sesuai dengan apa yang dikatakan (Appel dalam Chaer dan Agustina, 1995:141) Alih kode adalah gejala peralihan pemakaian bahasa karena perubahan situasi.

Menurut Allan Bell (dalam Coupland dan Adam, 1997:240) variasi bahasa adlah salah satu aspek paling menarik dalam sosiolingiustik. Prinsip dasar dari variasi bahasaa ini adalah penutur tidak selalu berbicara dalam cara yang sama dalam semua peristiwa atau kejadian, sehingga variasi bahasa ini seringkali muncul dalam percakapan. Alih kode sendiri merupakan bagian dari variasi bahasa. Alih kode muncul agar penutur dapat menyampaikan pesan kepada lawan tutur dengan baik.

Secara garis besar penggunaan alih kode oleh guru dalam kegiatan belajar mengajar agar supaya siswa dapat memahami materi dengan baik. Alih kode yang muncul ketika guru mengajar dalam kelas yaitu bahasa Indonesia beralih ke bahasa Melayu Manado.

\section{KESIMPULAN}

Alih Kode yang terjadi dalam penggunaan bahasa Indonesia oleh guru di kelas adalah alih kode bahasa melayu Manado (BMM), hal ini merupakan suatu hl yang lazim terjadi bagi pengguna dua tau lebih bahasa. Guru juga ketika mengajar menggunakan bahasa Indonesia yang baku (BIB) yang beralih kode dengan BMM bahkan campur kode antara BIB, BII, dan BMM. Alih kode terjadi pada konteks yang berkaitan dengan kehidupan siswa. 


\section{DAFTAR PUSTAKA}

Arifin, F. Zaenal . 2000. Cermat berbahasa Indonesia. Jakarta : Akapress

Alwi, Hassan, Dkk. 2003. Tata bahasa Baku Bahasa Indonesia (edisi ketiga).

Jakarta : Balai Pustaka

Chaer, Abdul Drs. 2007. Linguistik Umum. Jakarrta : PT. Rineka Cipta.

Chaer, A \& Agustina L. 2010. Sosiolinguistik Perkenalan Awal.

Jakarta : Rineka Cipta

Coupland, Nikolas and Adam Jaworski. 1997. Sosiolinguistics : A Reader and Coursbook. England. Macmillan Press LTD

Fishman, Joshua A. 1976. The Journal of Social Issues. Washington DC

Kridalaksana, Harimurti. 1985. Fungsi Bahasa dan Sikap Bahasa. Ende Flores : Nusa Indah

Made, J G I. 2010. Sociolinguistic The Study Of Societies Languages. Yogyakarta

: Graha Ilmu

Moleong, lexy J.. 2010. Metodologi Penelitian Kualitatif.

Bandung Remaja Rosdakarya.

Ohoiwutun, Paul. 2007. Sosiolinguistik Memahami Bahasa dalam Konteks

Masyarakat dan Kebudayaan. Jakarta : Kesaint Blanc.

Romaine, Susanne. 1998. Bilingualism. Oxfoard : Bassil Blackwell

Sugiyono. 2010. Metode Penelitian Kuantitatif Kualitatif \& RND. Bandung : Alfabeta.

Walija. 1996. Bahasa Indonesia dalam Perbincangan. Jakarta : IKIP 